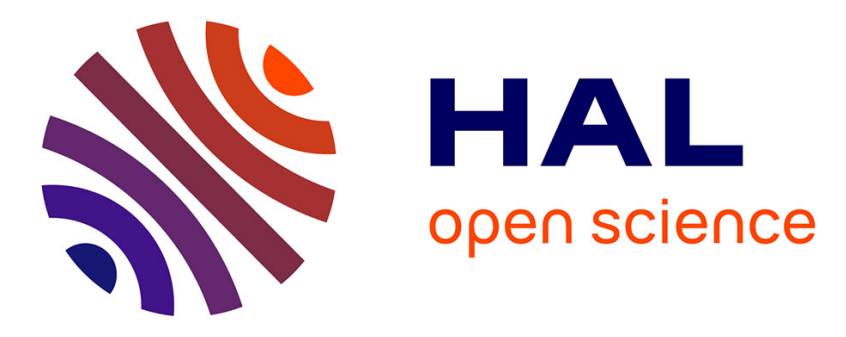

\title{
Can duckweed be used for the biomonitoring of textile effluents?
}

\author{
Imene Hocini, Khaled Benabbas, Nabila Khellaf, Hayet Djelal, Abdeltif
}

Amrane

\section{- To cite this version:}

Imene Hocini, Khaled Benabbas, Nabila Khellaf, Hayet Djelal, Abdeltif Amrane. Can duckweed be used for the biomonitoring of textile effluents?. Euro-Mediterranean Journal for Environmental Integration, 2019, 4 (1), pp.34. 10.1007/s41207-019-0126-9 . hal-02359967

\section{HAL Id: hal-02359967 https://hal-univ-rennes1.archives-ouvertes.fr/hal-02359967}

Submitted on 12 Feb 2020

HAL is a multi-disciplinary open access archive for the deposit and dissemination of scientific research documents, whether they are published or not. The documents may come from teaching and research institutions in France or abroad, or from public or private research centers.
L'archive ouverte pluridisciplinaire HAL, est destinée au dépôt et à la diffusion de documents scientifiques de niveau recherche, publiés ou non, émanant des établissements d'enseignement et de recherche français ou étrangers, des laboratoires publics ou privés. 


\section{Can duckweed be used for biomonitoring of textile effluents?}

Imene HOCINI a ${ }^{\text {a }}$ Khaled BENABBAS ${ }^{\text {a }}$, Nabila KHELLAF ${ }^{\text {a,* }}$, Hayet DJELAL ${ }^{\text {b }}$, Abdeltif AMRANE ${ }^{\mathrm{C}}$

${ }^{a}$ Department of Process Engineering, Faculty of Engineering, Badji Mokhtar University, LOMOP, P.O. Box 12, 23000 Annaba, Algeria

${ }^{b}$ UniLaSalle-Ecole des Métiers de l'Environnement, Campus de Ker Lann, 35170 Bruz, France

${ }^{c}$ Université de Rennes 1, ENSCR, CNRS, UMR 6226, CS 50837, 35708 Rennes, France

Corresponding author: khellafdaas@yahoo.fr (N. KHELLAF)

Tel: +213 38876560

ORCID: 0000-0001-8625-6135

\section{Acknowledgments}

The authors thank the Ministry of Higher Education and Scientific Research, Algeria for the financial support through the CNEPRU project $\mathrm{N}^{\circ}$ A16N01UN230120150004. 


\section{Abstract}

2 In certain countries, poorly managed freshwaters need to be seriously controlled to not lead to ecosystems

3 degradation. This control can be achieved by a biomonitoring using living organisms as ecological alert

4 indicators. In this context, biotests were undertaken on Lemna gibba (L. gibba) to assess the toxic effect of textile pollutants reaching a natural ecosystem. $L$. gibba were exposed to different concentrations $(5-100 \mathrm{mg} / \mathrm{L})$ of two dyes, namely Direct Red 89 (DR-89) and Vat Blue 20 (VB-20), under laboratory conditions. Our findings showed that at concentrations $>50 \mathrm{mg} / \mathrm{L}$, visible damage of toxicity (chlorosis and dislocation of fronds) were appeared from the third day of toxicity tests leading to serious necrosis. However, at dye concentration $\leq 50$ $\mathrm{mg} / \mathrm{L}$, duckweed showed no visible signs of toxicity within an exposure time of 4 days. However, these concentrations exhibited a significant inhibition in $L$. gibba growth rate with a clear abatement in the photosynthetic pigments contents. The dye concentration that reduces by $50 \%$ the growth rate of the plants (IC50) was 36.3 and $26.9 \mathrm{mg} / \mathrm{L}$ for DR-89 and VB-20, respectively. The concentration-dependant reduction in growth and photosynthetic pigments demonstrated their sensitivity in detection of dyes in aquatic systems. The current findings proving physiological alterations of $L$. gibba following dye exposure, suggested that the species are strongly suitable for the testing of textile effluents contaminating water bodies.

Keywords: Biomonitoring; Lemna gibba; dye pollutant; Photosynthetic pigments; Toxicity test.

\section{Introduction}

The urban industrialization and population growth have placed an escalating pressure on our environment by discharging organic and inorganic pollutants in atmospheric, terrestrial and aquatic ecosystems. This fact led to a threat in human and animal health and a disturbance in the ecological balance (Khataee et al. 2012; Padmesh et al. 2005). Among the most dangerous effluents, the textile industry handles nearly one million tons of synthetic dyes. Ten percent of these dyes are released into natural ecosystems following inefficiencies in dying or loss of dye products during textile processes (Jadhav et al. 2010). Although the textile effluents are treated in wastewater plants, the big majority of them is bio-recalcitrant and can easily escape to reach the nature. They can contaminate the water bodies because of the poorly managed plants in certain developing countries (Mangadze et al. 2019). The colored effluents are a serious ecological concern because of their potential toxicity to aquatic life with eventual carcinogenic and mutagenic effects (Ventura-Camargo et al. 2016). Additionally, these nonbiodegradable compounds can contribute to strong coloration of water even at low concentration reducing 
sunlight penetration into the water. Moreover, dying effluents can enter terrestrial systems and contaminate the agriculture lands leading to serious health implications as recently reported (Raziq et al., 2017). It is therefore essential to ascertain the toxicity threshold of dye products in order to detect and assess their impact on biotic systems.

For pollutant analysis purposes, a wide range of approaches is adopted including the direct chemical analysis and physical detection. The direct chemical analysis has several disadvantages such as complex procedures for the preparation of samples, the expensive chemicals requirement and the interference caused by the secondary pollutants during the analysis (Park et al., 2012). In addition, this approach does not take into account the temporal changes of the exposure or interactive effects of pollutants (Kumar and Han, 2010). On the other hand, physical methods require strong and often expensive and heavy equipment. To compensate these limitations, various biological tests have been developed with standardization of the hazard and risk assessment to identify exposure value and adverse effects of pollutants on human health and the environment (Hund-Rinke et al., 2016). Particularly, plant-based bioassays have gained remarkable popularity among the toxicological assessment procedures. Those bioassays include the use of aquatic plants that can provide information on the toxic effects of certain pollutants (Siddiqui et al., 2011; Eullaffroy and Vernet, 2003). In certain Mediterranean countries, such Algeria where the management of aquatic systems is still difficult, aquatic macrophytes have attracted the interest of researchers in recent years for elaborating toxicity tests (Alonso et al., 2018; Böcük et al., 2013; Wang, 1990). Among these aquatic organisms, duckweed may perhaps be used as ecological alert indicator to measure the phytotoxicity of synthetic dyes (Böcük et al., 2013; Cleuvers and Ratte, 2002).

The duckweed Lemna gibba is a small floating plant belonging to the family of Lemnaceae. It is found on the surface of eutrophic backwater or slow flows of fresh and brackish waters forming green dense carpets (Driever et al., 2005). Lemna is a very appropriate species for the toxicity tests with its simple structure, rapid growth and high tolerance to different stresses and part of an international standard protocol (OECD, 2006). Duckweed species have been previously used in toxicity tests and applied as bioindicator for detecting several pollutants in aquatic environment (Türker et al., 2016; Khellaf and Zerdaoui, 2010; Sinha et al., 1995). Studies detailing the effect of dyes effluents on these aquatic species warrant to be deepened to complete data reported in the literature which are still insufficient since they concern only few pollutants and few plant species. The first objective of the present work is to ascertain the toxicity effects of two dyes on the morphology and physiology 
60

61

62

63

64

65

66

67

68

69

70

71

72

73

74

75

76

77

78

(DR-89) and Vat Blue 20 (VB-20). The effect of these two pollutants was determined from the concentration that reduces by $50 \%$ the growth rate of the plants (IC50), the lowest observed effect concentration (LOEC) and the no-observed effect concentration (NOEC). Additionally, the degree of pollutant inhibition on the concentration of photosynthetic pigments (chlorophyll-a, chlorophyll-b and total carotenoids) was evaluated.

\section{Experimental}

\subsection{Plant selection and culture conditions}

The species used in this study was L. gibba obtained from a natural pond located in Northeastern Algeria. The plants were transported to the laboratory in plastic containers filled with water from the pond. The healthy fronds with roots characterized by a green color were selected for conducting the different experiments. The plants were gently rinsed with tap water and distilled water to eliminate debris then placed in a wide aquarium containing a nutrient medium (Bajaj et al., 2008). The culture medium contained macronutrients $\left(\mathrm{NH}_{4} \mathrm{NO}_{3}\right.$, $\mathrm{KNO}_{3}, \mathrm{KH}_{2} \mathrm{PO}_{4}, \mathrm{MgSO}_{4} .7 \mathrm{H}_{2} \mathrm{O}, \mathrm{NaCl}, \mathrm{K}_{2} \mathrm{HPO}_{4}$ and $\left.\mathrm{Ca}\left(\mathrm{NO}_{3}\right)_{2}, 4 \mathrm{H}_{2} \mathrm{O}\right)$ and micronutrients $\left(\mathrm{MnSO}_{4} \cdot \mathrm{H}_{2} \mathrm{O}, \mathrm{H}_{3} \mathrm{BO}_{3}\right.$, $\left.\mathrm{ZnSO}_{4} .7 \mathrm{H}_{2} \mathrm{O}, \mathrm{CuSO}_{4} .5 \mathrm{H}_{2} \mathrm{O}, \mathrm{Na}_{2} \mathrm{MoO}_{4} \cdot 2 \mathrm{H}_{2} \mathrm{O}, \mathrm{NiCl}_{2} \cdot 6 \mathrm{H}_{2} \mathrm{O}, \mathrm{FeSO}_{4} \cdot 7 \mathrm{H}_{2} \mathrm{O}\right)$. The aquatic plants were left in growth for three days before the beginning of the tests. The laboratory conditions were as follows: $\mathrm{pH}=$ $6.1 \pm 0.01, \mathrm{~T}=21 \pm 1{ }^{\circ} \mathrm{C}$, photoperiod $=12 \mathrm{~h}$. A system of continuous aeration was used to provide oxygen for the Lemna fronds and prevent fungal diseases (Kamal et al., 2004).

\subsection{Chemicals}

Two textile dyes were selected as organic pollutants: Direct Red 89 (DR-89) and Vat Blue 20 (VB-20). Some of their physicochemical characteristics and chemical structures are given in Table 1. The other chemicals $(\mathrm{HCl}$, $\mathrm{NaOH}$ and nutrients) were purchased from Merck. All the solutions were prepared using distilled water $(\mathrm{pH}=$ $6.5, \lambda=1.76 \mu \mathrm{S} / \mathrm{cm})$. Stock solutions of DR-89 and VB-20 were prepared by dissolving $1 \mathrm{~g}$ of dye in $1 \mathrm{~L}$ distilled water and were kept in an incubator at a temperature of $4{ }^{\circ} \mathrm{C}$. The concentration of the two dyes was analyzed using a UV-vis Spectrophotometer (Screw SECOMAM Prim Light V9B S/N 2836). Dye concentration was evaluated by measuring the absorbance at the maximal wavelength of each dye (Table 1) and extrapolation onto the calibration curve that was carried out by using solutions with known DR-89 and VB-20 concentrations in the range of $0-15 \mathrm{mg} / \mathrm{L}$.

\subsection{Toxicity tests}


The protocol of toxicity tests was derived from a draft directive Standard 221 for a 4-days growth inhibition

89 (OECD, 2006). This test mimics a small artificial ecosystem. Nine to twelve fronds of Lemna (2 to 3 colonies) 90 were gently placed in crystallizing cups $(7 \mathrm{~cm}$ in height and $5 \mathrm{~cm}$ in diameter) containing $100 \mathrm{~mL}$ of nutrient 91 medium with different initial dye concentrations $(5-100 \mathrm{mg} / \mathrm{L})$ frequently detected in water samples from 92 WWTPs. They were immersed in a thermostated bath and placed in conditions similar to those of plant culture but without aeration as shown in Figure 1. The control tests (without dye) were carried out to compare the results and to calculate the growth rate of the plants according to Equation 2. All the biological tests (corresponding to ten initial concentrations) were carried in triplicates. The cups were randomized $\overline{\text { within }}$ the bath to avoid location effects. The dyes concentration range was fixed after observing morphological and toxicity behavior of the L. gibba on a daily bases (Khellaf and Zerdaoui, 2010). These visual symptoms of toxicity may appear in different ways such as chlorosis, dislocation of fronds and necrosis. Dye toxicity on duckweed may be also manifested as a decrease in the biomass, the growth rate and/or the photosynthetic pigments.

\subsection{Data analysis and toxicity assessment}

The estimation of duckweed growth was based on the fronds number; more specifically, all visible fronds were counted manually at initial $(t=0)$ and final time $(t=4$ days $)$ during the test period. The average growth rate (AGR) was calculated according to the guidelines of OECD (2006) as illustrated by the following equation (Eq. 1):

$$
\mathrm{AGR}=\frac{\ln \mathrm{Nj}-\ln \mathrm{Ni}}{\Delta \mathrm{t}}
$$

The percentage of inhibition of the growth rate (\% Ir) was determined using Eq. 2 (Gür et al., 2016):

$$
\% \mathrm{Ir}=\underset{\mathrm{AGRc}}{\mathrm{AGRc}-\mathrm{AGRt}}
$$

Where $\mathrm{Ni}$ and $\mathrm{Nj}$ are numbers of fronds at time $\mathrm{i}$ and $\mathrm{j}$, respectively; $\Delta \mathrm{t}$ is the period of experience (4 days);

AGRc and AGRt are the average growth rates of the control and the treatment, respectively.

The concentration inhibiting 50\% of the growth rate of $L . g i b b a$ in the presence of the two dyes is deduced from figure representing the percentage of inhibition of the growth rate versus the logarithmic concentrations. The validity of the present test is subject to value of the doubling time of frond number $\left(T_{d}\right)$. In the control, this value 
115

116

118

119

10

test must be less than 2.5 days according to the test protocol of OECD (2006). $T_{d}$ was assessed by the following equation (Eq. 3):

$$
\mathrm{T}_{\mathrm{d}}=\frac{\ln 2}{\mathrm{AGRc}}
$$

In order to illustrate the physiological state of the used L. gibba, chlorophyll and carotenoid pigments were quantified. $0.1 \mathrm{~g}$ of fresh material was grounded and homogenized in $100 \%$ acetone $(100 \mathrm{ml})$, centrifuged at $2000 \mathrm{~g}$ for $10 \mathrm{~min}$ and the absorbance of the supernatant was measured by a UV-vis spectrophotometer (Screw Secomam Prim Light V9B S/N 2836) at 470, 661 and 664 nm (Vafaei et al., 2012). Chlorophyll-a, chlorophyll b and carotenoids were calculated using the following equations (Eq. 4-9) as previously described by Hartmut et al. (2001).

$$
\begin{aligned}
& \text { Chla }(\mathrm{mg} / \mathrm{L})=11.24 \times \mathrm{A}_{661}-2.04 \times \mathrm{A}_{664} \\
& \text { Chla }(\mathrm{mg} / \mathrm{g})=\text { Chla }(\mathrm{mg} / \mathrm{L}) \times(0.01 \text { Lacetone } / 0.2 \mathrm{~g} \text { frond }) \\
& \text { Chlb }(\mathrm{mg} / \mathrm{L})=20.13 \times \mathrm{A}_{664}-4.19 \times \mathrm{A}_{661} \\
& \text { Chlb }(\mathrm{mg} / \mathrm{g})=\operatorname{Chlb}(\mathrm{mg} / \mathrm{L}) \times(0.01 \text { Lacetone } / 0.2 \mathrm{~g} \text { frond }) \\
& \mathrm{C}_{\mathrm{X}+\mathrm{C}}(\mathrm{mg} / \mathrm{L})=\left(1000 \mathrm{~A}_{470}-1.90 \text { Chla }-63.14 \mathrm{Chlb}\right) / 214 \\
& \mathrm{C}_{\mathrm{X}+\mathrm{C}}(\mathrm{mg} / \mathrm{g})=\mathrm{C}_{\mathrm{X}+\mathrm{C}}(\mathrm{mg} / \mathrm{L}) \times(0.01 \text { Lacetone } / 0.2 \mathrm{~g} \text { frond })
\end{aligned}
$$

\subsection{Statistical analysis}

132 Three independent experiments were performed for each of the ten dye concentrations. Error bars given in the 133 figures represent standard deviation of the means. The results were analyzed using a one-way analysis of 134 variance (ANOVA). Comparison between control and treatments was statistically analyzed and the validity of 135 investigation was expressed as probability value of $\mathrm{p}<0.05$.

\section{3. Results}

\subsection{Symptoms of toxicity}

138 To determine the effect of DR-89 and VB-20 on L. gibba, morphological symptoms of toxicity were identified.

139 The fronds were daily observed, and the results show that the two dyes caused visible damages on the plants as 140 shown in Figure 2 at concentrations $>50 \mathrm{mg} / \mathrm{L}$. These damages were visible from the second day of exposure 
141 for DR-89 and from the third day of exposure for VB-20. Additionally, DR-89 exhibited more sign of toxicity

142 than VB-20. The signs of toxicity consisted on a dislocation of fronds followed by a reduction in biomass for 143 concentrations > $50 \mathrm{mg} / \mathrm{L}$. At high concentrations $(100 \mathrm{mg} / \mathrm{L})$, a rapid chlorosis of some fronds was observed 144 where their color changed from green to yellow for both dyes. These signs progressed to necrosis of small fronds 145 at the end of toxicity tests.

\section{3.2. Dose-Growth rate relationship}

147 The toxic effects of the used dyes in this study were evaluated by the average growth rate inhibition calculated

\subsection{Effect of VB-20 and DR-89 on the content of chlorophyll and carotenoid pigments}


The concentrations of photosynthetic pigments, namely chlorophyll-a (Ch-a), chlorophyll-b (Ch-b) and total carotenoids $\left(\mathrm{Cx}_{+} \mathrm{c}\right)$ (xanthophylls and carotenes) were analyzed quantitatively in order to measure the response of L. gibba to the stress induced by the two dyes $\left(\mathrm{C}_{0}=10-50 \mathrm{mg} / \mathrm{L}\right)$. Figure 4 shows the alteration of the different pigment content as a function of dye concentration. The results show that chlorophyll-a content was significantly affected by the presence of the dyes. It decreased by $30 \%$ and $32 \%$ after 4 days of treatment with $50 \mathrm{mg} / \mathrm{L}$ of VB-20 and DR-89, respectively. The amount of chlorophyll-b content also decreased significantly by $36 \%$ and $54 \%$ at the same conditions for VB-20 and DR-89, respectively. Carotenoids content exhibited a reduction of $26 \%$ and $35 \%$ in response to VB-20 and DR-89 exposure, respectively.

To fit the relation between pigment content and initial dye concentration, we used linear regression equations that showed linearity with coefficients of determination varying from 0.938 to 0.983 as shown in Table 3 .

\section{Fig. 4}

\section{Table 3}

\section{4. Discussions}

182 The present study was undertaken with the specific aims to evaluate the degree of dye inhibition to L. gibba 183 growth and to investigate the deleterious effects of the pollutants on chloroplastic pigments in order to test the 184 feasibility of using duckweed as contaminant bioindicator. Biochemical and physiological effects of chemical pollutants on several duckweed species were extensively studied (Singh et al., 2018; Sree et al., 2018; Appenroth et al., 2010; Khellaf and Zerdaoui, 2010) and literature on the effect of organic pollutants such as synthetic dyes deserves to be enriched. The results of the present study show that, at dye concentration $>50$ $\mathrm{mg} / \mathrm{L}$, morphological symptoms of toxicity were induced. The signs consisted on a dislocation of fronds and/or a rapid chlorosis of some fronds. These signs progressed to necrosis of small fronds at the end of the treatment tests. Several researchers asserted that visible symptoms of toxicity in living organisms could be an efficient indicator to assess the deleterious effects of some mineral and organic pollutants (Costa et al., 2018; Song et al., 2015; Coronado-Posada et al., 2013; Henke et al., 2011). Furthermore, some researchers suggested to take into account the importance of identifying the suitable endpoints of toxicity assessment and to consider the intrinsic differences between species when evaluating the toxicological effect of pollutants (Song et al., 2015). Several published studies define plant growth such as the increase in an observable parameter like the frond number, total frond area, dry weight or the chlorophyll content (Mkandawire et al., 2006; Mazur et al., 2018). In this project, the growth was expressed as average growth rate based on fronds number. The different assays 
198 confirmed that the aquatic plant reacts to the two dyes by changes in the growth rate. Inhibition of the growth

was observed in all experiments as shown in Figure 2. This may be caused by an inhibition of cell division resulting from oxidative stress or alteration of the plant photosystem following a reduction in the electron transport of chloroplasts (Sree et al., 2018). Vafaei et al. (2012) attributed the reduction of growth-rate to the dye inhibitory effect of photosynthesis and/or the synthesis of growth proteins. Some studies reported the effect of various pollutants on several species of aquatic plants. Khataee et al. (2012) found that the relative growth rate (RGR) of $L$. minor was negatively influenced by the increase of the concentration of Acid Blue 92 . Additionally, RGR of the same species decreased with an increase in the initial concentration of Methylene Blue (Reema et al., 2011). Similar results reported by Khataee et al., 2013 indicated that the exposure of Azolla filiculoides to Acid Blue 92 resulted in a growth reduction with the increase of the dye concentration (10 and 20 $\mathrm{mg} / \mathrm{L}$ ). Vafaei and al. (2012) demonstrated that the exposure of this plant species to the dye Basic Red 46 (10 and $20 \mathrm{mg} / \mathrm{L}$ ) reduced the value of RGR by 26.83 and $32.05 \%$, respectively compared to the control. In the present study, it was found that $36.31 \mathrm{mg} / \mathrm{L}$ of VB-20 and $26.92 \mathrm{mg} / \mathrm{L}$ of DR-89 reduced the RGR of $L$. gibba by $50 \%$; additionally, photosynthetic pigments content exhibited a significant reduction in response to VB-20 and DR-89 exposure. The intensity level of toxicity varies from one species to another, which could be due to their behavioral responses and their origin.

In the present study, some differences were found between $L$. gibba development patterns during contact with the two pollutants. The red dye had a more aggressive impact on the duckweed development; indeed, the growth rate was inhibited by 80 and $65 \%$ in the presence of $50 \mathrm{mg} / \mathrm{L}$ of DR- 89 and VB-20, respectively. The results also demonstrated that concentrations of $26.92 \mathrm{mg} / \mathrm{L}$ DR- 89 and $\mathrm{mg} / \mathrm{L} 36.31 \mathrm{VB}-20$ in the culture medium reduced the growth by $50 \%$. These values can be used as indicator indices in biomonitoring of water textile pollution. The inhibitory effect of the two pollutants on the photosynthetic pigments was also highlighted. Low chlorophyll and carotenoid pigments in the polluted media were observed compared to the control. This indicates the relative damages to the photosynthetic cellular machinery (Vafaei et al., 2012). The decrease of photosynthetic pigment levels under different dyes exposure is a direct reason for the reduction in the biomass and the relative growth rate of L. gibba. Several studies have reported similar results. Türker et al. (2016) asserted that the concentration of photosynthetic pigments $\left(\mathrm{Ch}-\mathrm{a}, \mathrm{Ch}-\mathrm{b}\right.$ and $\left.\mathrm{Cx}_{+} \mathrm{c}\right)$ decreased in $L$. gibba exposed to boron concentration of $8 \mathrm{mg} / \mathrm{L}$. Another study carried out by Khataee et al. (2013) on Azolla filiculoides exposed to 10 and $20 \mathrm{mg} / \mathrm{L}$ Acid Blue 92 solutions showed that $\mathrm{Ch}-\mathrm{a}$, Ch-b and $\mathrm{Cx}_{+} \mathrm{c}$ concentrations decreased in both cases compared to the control. The critical interference on the chloroplastic pigments could be due to the inhibition of 
228 the photosynthetic electron transport and decomposition of the chloroplast membrane (Sandmann and Böger,

1980). According to Sree et al. (2015), a pollutant present in the culture medium inhibits the involved enzymes in the synthesis of chlorophyll intermediates like 5-aminolevulinic acid and protoporphyrin.

Regarding the physiological changes following dyes exposure, a relationship was found between initial pollutant concentration and the physiological affecting parameter (e.g. growth and photosynthetic pigments) using linear regression models. These models are beneficial to verify the validity and reproducibility of the toxicity tests. Additionally, these models should provide scientific support to reduce uncertainties of the risk assessment of dyes; this can help risk manager to act in the interaction of exposure, effects, risk and uncertainties. Finally, it can be concluded that morphological and physiological changes in the duckweed L. gibba following exposure to pollutants can be used in testing of dye(s) pollution.

\section{Conclusion}

In this work, we studied the morphological and physiological behavior of L. gibba in the presence of dyes. We found that the duckweed L. gibba could be used for testing dye-contaminated water. Visually, the duckweed tolerated the two textile dyes (DR-89and VB-20) up to $50 \mathrm{mg} / \mathrm{L}$ in a nutrient medium without manifesting significant symptoms of toxicity. Although no visible damage was observed on the morphological aspect of the macrophyte at concentration $\leq 50 \mathrm{mg} / \mathrm{L}$, there was a significant decrease in the growth rate and reduction in the photosynthetic pigments content (chlorophyll and carotenoid) after an exposure of 4 days. Lemna gibba could be taken as potential indicator of dye pollutants. These results must be combined with field investigations to prove that this indicator species could be a useful management tool to determine the quality of freshwater system impacted by textile industry or agro-alimentary factories releasing dyes to the environment.

\section{Funding sources}

250 Ministry of Higher Education and Scientific Research, Algeria

\section{Conflict of interest statement}

253 On behalf of all authors, the corresponding author states that there are no conflicts of interest.

\section{References}


Alonso X., Hadad H.R., Córdoba C., Polla W., Reyes M.S., Fernández V., Marino L., Villalba A. (2018) Macrophytes as potential biomonitors in peri-urban wetlands of the Middle Parana River (Argentina). Environ. Sci. Pollut. Res. 25(1): 312-323.

Appenroth K-J., Krech K., Keresztes Á., Fischer W., Koloczek H. (2010) Effects of nickel on the chloroplasts of the duckweeds Spirodela polyrhiza and Lemna minor and their possible use in biomonitoring and phytoremediation. Chemosphere 78: 216-223.

Appenroth K-J. (2015) Phytotoxicity of cobalt ions on the duckweed Lemna minor Morphology, ion uptake, and starch accumulation. Chemosphere 131: 149-156.

Bajaj M., Gallery C., winter I. (2008) Biodegradation of high phenol containing synthetic wastewater by year anaerobic fixed bed reactor. Bioresour. Technol. 99: 8376-8381.

Böcük H., Yakar A., Can O.F. (2013) Assessment of Lemna gibba L. (duckweed) as a potential ecological indicator for contaminated aquatic ecosystem by boron mine effluent. Ecol. Indicators, 29: 538-548.

Cleuvers M., Ratte H-T. (2002) Phytotoxicity of coloured substances: is Lemna Duckweed an alternative to the algal growth inhibition test? Chemosphere 49(1): 9-15.

Coronado-Posada, N., Cabarcas-Montalvo M., Olivero-Verbel J. (2013) Phytotoxicity assessment of a methanolic coal dust extract in Lemna minor. Ecotoxicol. Environ. Safety 95 : 27-32.

Costa M.B., Tavares F.V., Martinez C.B., Colares I.G., Martins C.D.M.G. (2018) Accumulation and effects of copper on aquatic macrophytes Potamogeton pectinatus L.: Potential application to environmental monitoring and phytoremediation. Ecotoxicol. Environ. Safety 155: 117-124.

Driever S. M., Nes E.H.V., Roijackers, R.M.M. (2005) Growth limitation of Lemna minor due to high plant density. Aquat. Bot. 81: 245-251.

Eullaffroy P., Vernet G. (2003) The F684/F735 chlorophyll fluorescence ratio: a potential tool for rapid detection and determination of herbicide phytotoxicity in algae. Water Res.: 37, 1983-1990.

Gajic G., Mitrovic M., Pavlovic P., Stevanovic B., Djurdjevic L., Kostic O. (2009) An assessment of the tolerance of Ligustrum ovalifolium Hassk. To traffic -generated $\mathrm{Pb}$ using physiological and biochemical markers. Ecotoxicol. Environ. Safety 72: 1090-1101.

282 Henke R., Eberius M., Appenroth K-J. (2011) Induction of fronf abscission by metals and other toxic compounds in Lemna minor. Aquat. Toxicol. 101(1): 261-265. 
284

285

286

287

288

289

11

12290

13

14291

15

16292

17

18293

19

20294

21

22295

23

24296

25

26297

27

28298

29

30299

31

Hund-Rinke K., Baun A., Cupi D., Fernandes T.F., Handy R., et al. (2016) Regulatory Ecotoxicity Testing of Nanomaterials Proposed Modifications of OECD Test Guidelines Based on Laboratory Experience with Silver and Titanium Dioxide nanoparticles. Nanotoxicology 10(10): 1442-1447.

Jadhav J. P., Phugar S.S, Dhanve R.S., Jadhav S.B. (2010) Rapid biodegradation and decolorization of Direct Orange 39 (orange TGLL) by an isolated bacterium Pseudomonas aeruginosa strain BCH', Biodegradation 21(3): 453-463.

Kamal M., Ghali A.E., Mahmoud N., Coté R. (2004) Phytoaccumulation of heavy metals by aquatic plants, Environ. Inter. 92: 1029-1039.

Khataee A.R., Movafeghi A., Torbati S., Lisar S.Y.S., Zarei M. (2012) Phytoremediation potential of duckweed (Lemna minor L.) in degradation of C.I. Acid Blue 92: Artificial neural network modeling. Ecotoxicol. Environ. Safety 80: 291-298

Khataee A.R., Movafeghi A., Vafaei F., Lisar SYS. Zarei M. (2013) Potential of the aquatic fern azolla filiculoides in biodegradation of an azo dye: modeling of experimental results by artificial neural networks. Inter. J. Phytoremed. 15: 729-742.

Khellaf N., Zerdaoui M. 2010) Growth, photosynthesis and respiratory response to copper in Lemna minor: A potential use of duckweed in biomonitoring. Iran. J. Environ. Health Sci. Eng. 7 (2): 299-306.

Kumar K.S., Han T. (2010) Physiological response of Lemna species to herbicides and its likely use in toxicity testing. Toxicol. Environ. Health Sci. 2: 39-49.

Lichtenthaler H.K., Buschmann C. 2001) Chlorophylls and Carotenoids: Measurement and Characterization by UV-VIS Spectroscopy. Current Protocols in Food Analytical Chemistry, F4.3.1-F4.3.8, John Wiley \& Sons, Inc.

Mangadze T., Dalu T., Froneman P.W. (2019) Biological monitoring in southern Africa: A review of the current status, challenges and future prospects. Sci. Total Environ. 648: 1492-1499.

Mazur R., Szoszkiewicz K., Lewicki P., Bedla D. (2018) The use of computer image analysis in a Lemna minor L. bioassay. Hydrobilogia 812(1): 193-201.

311 Mkandawire K., Taubert B., Dudel E.G. (2006) Limitations of growth-parameters in Lemna gibba bioassays for 312 arsenic and uranium under variable phosphate availability. Ecotoxicol. Environ. Safety 65: 118-128.

313 OECD (2006) Guidelines for testing of chemicals, Lemna, Growth Inhibition Test. Draft Guideline, $221,22$. 
314

315

316

317

318

319

11

12320

13

14321

15

16322

17

18323

19

20324

21

22325

23

24326

25

26 327

27

$\begin{array}{ll}28 & 328\end{array}$

29

$\begin{array}{ll}30 & 329\end{array}$

31

32330

33

34331

35

Padmesh T.V.N., Vijayaraghavan K., Sekaran G., Velan M. (2005) Batch and column studies on biosorption of acid dyes on fresh water macro algae Azolla Filiculoides. J. hazard. Mater. 125: 121-129.

Park J.-S., Brown M.T., Han T. (2012) Phenol toxicity to the aquatic macrophytes Lemna Paucicostata. Aquat. Toxicol. 7: 73-81.

Raziq M., Kooh R., Lim L.B.L., Lim L.H., Malik O.A. (2017) Phytoextraction potential of water fern (Azolla pinnata) in the removal of a hazardous dye, methyl violet 2B: Artificial neural network modelling. Inter. J. Phytoremed. 20(5): 424-431.

Reema R.M., Saravanan P., Kumar M.D., Renganathan S. (2011) Accumulation of Methylene Blue Dye by Growing Lemna minor. Separ. Sci.Technol. 46: 1052-1058.

Sandmann G., Böger P. (1980) Copper Deficiency and Toxicity in Scenedesmus. Zeitschrift für Pflanzenphysiologie 98(1): 53-59.

Siddiqui A.H., Tabrez S., Ahmad M. (2011) Validation of plant based bioassays for the toxicity testing of Indian waters. Environ. Monitor. Assessment 179(1-4): 241-253.

Sinha S., Rai U.N., Chandra P. (1995) Modulation of cadmium uptake and toxicity in Spirodela polyrrhiza (L.) schleiden due to malathion. Environ. Monitor. Assess 38(1): 67-73.

Singh V., Pandey B., Suthar S. (2018) Phytotoxicity of amoxicillin to the duckweed Spirodela polyrhiza: Growth, oxidative stress, biochemical traits and antibiotic degradation. Chemosphere 201: 492-502.

Song L., Vijver M.G., Peijnenburg W.J.G.M. (2015) Comparative toxicity of copper nanoparticles across three Lemnaceae species. Sci. Total Environ. 518-519: 217-224

Sree K.S., Keresztes Á., Mueller-Roeber B., Brandt R., Eberius M., Fischer W., Appenroth K-J. (2015) Phytotoxicity of cobalt ions on the duckweed Lemna minor-Morphology, ion uptake, and starch accumulation. Chemosphere 131: 149-156.

Türker O.C., Gür N., Bocük H. (2016) Toxicity assessment of boron (B) by Lemna minor L. and Lemna gibba L. and their possible use as model plants for ecological risk assessment of aquatic ecosystems with boron pollution. Chemosphere, 157: 1-9.

Vafaei F, Khataee AR, Movafeghi A., Lisar S.Y.S., Zarei M. (2012) Bioremoval of an azo dye by Azolla filiculoides: Study of growth, photosynthetic pigments and antioxidant enzymes status. Inter. Biodeterior. Biodegrad. 75: 194-200. 
342 Ventura-Camargo B.C., de Angelis D.F., Marin-Morales M.A. (2016) Assessment of the cytotoxic, genotoxic 1343 and mutagenic effects of the commercial black dye in Allium cepa cells before and after bacterial 2
3 $344 \quad$ biodegradation treatment. Chemosphere 161: 325-332.

4
5
6
7
8
9

345 Wang W. (1990) Literature Review on duckweed toxicity testing: Environ. Res. 51, 7-22. 346 
Table 1 Physicochemical data and chemical structures of the two dyes under study

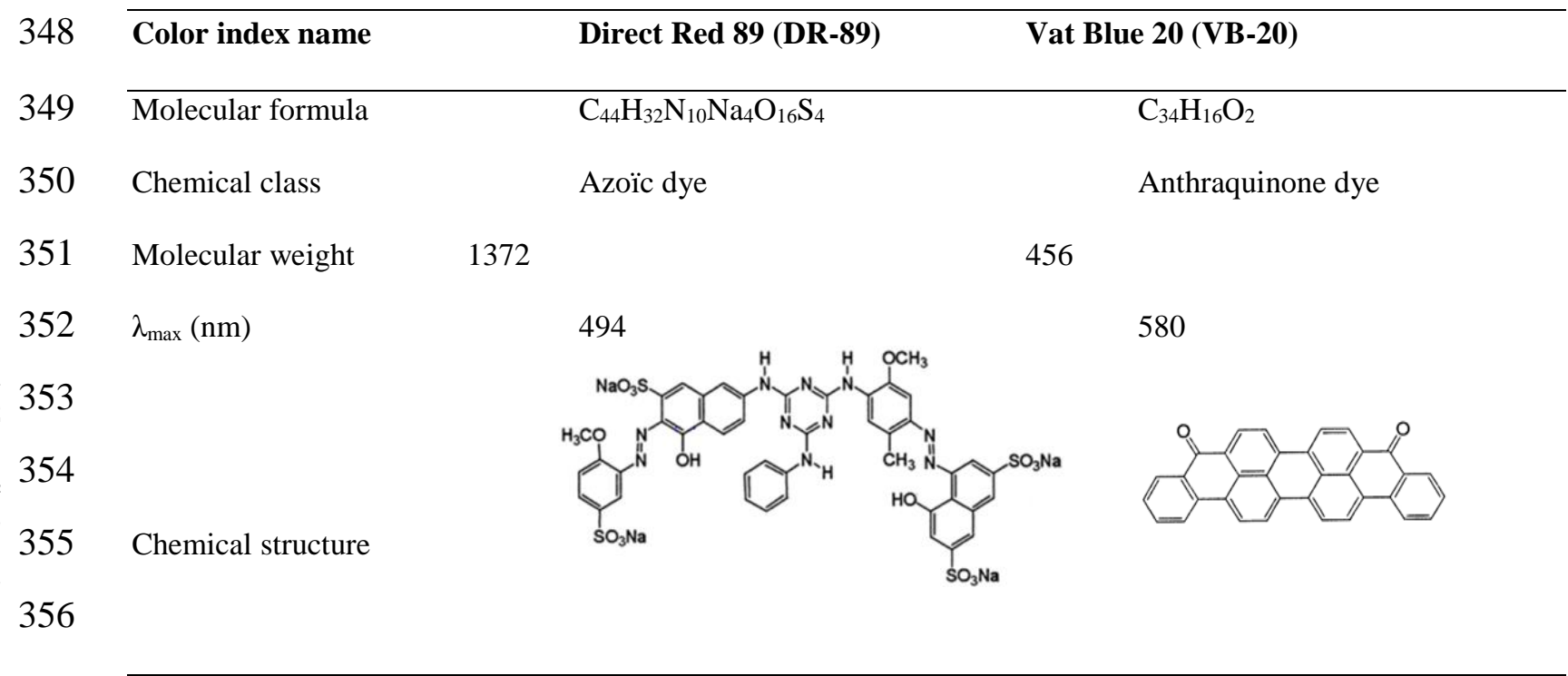

Table 2 Growth inhibition parameters of L. gibba in the presence of the dyes

\begin{tabular}{lllll}
\hline Dye & IC50 & $\mathbf{R}^{2}$ & LOEC & NOEC \\
& $(\mathrm{mg} / \mathrm{L})$ & $(/)$ & $(\mathrm{mg} / \mathrm{L})$ & $(\mathrm{mg} / \mathrm{L})$ \\
\hline DR-89 & 26.92 & 0.88 & 5 & $*$ \\
VB-20 & 36.31 & 0.98 & 5 & $*$ \\
\hline Not observed & & &
\end{tabular}

\section{* Not observed}

Table 3 Linear regression models: pigment content versus initial dye concentration

\begin{tabular}{|c|c|c|c|}
\hline & Pigment & Regression equations & $\mathbf{R}^{2}$ \\
\hline \multirow{3}{*}{$\begin{array}{l}2 \\
\infty \\
\dot{\alpha} \\
\stackrel{1}{0}\end{array}$} & Chl-a & $Y=-0.029 x+0.517$ & 0.963 \\
\hline & Chl-b & $Y=-0.027 x+0.281$ & 0.957 \\
\hline & Carotenoid & $Y=-0.009 x+0.151$ & 0.938 \\
\hline$\stackrel{\Upsilon}{\sim}$ & Chl-a & $Y=-0.032 x+0.542$ & 0.958 \\
\hline \multirow{2}{*}{$p^{\prime}$} & Chl-b & $Y=-0.018 x+0.270$ & 0.987 \\
\hline & Carotenoid & $Y=-0.007 x+0.157$ & 0.983 \\
\hline
\end{tabular}

$\overline{\mathrm{Y}, \mathrm{X} \text { and } \mathrm{R}^{2} \text { represent the pigment content }(\mathrm{mg} / \mathrm{g} \mathrm{FW}) \text {, the initial dye concentration (mg/L) }}$

and the coefficient of determination, respectively 


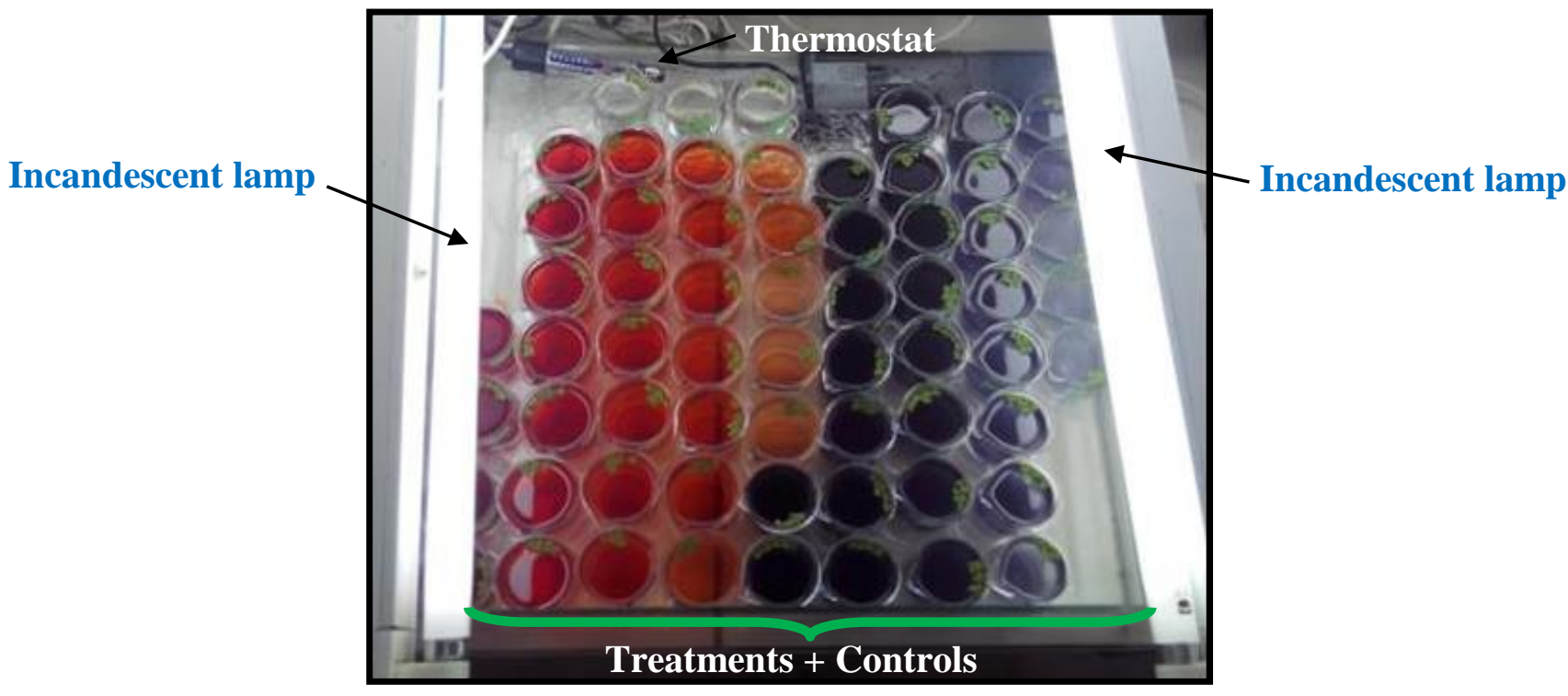

Fig. 1 Experimental setup for the phyto-toxicity tests

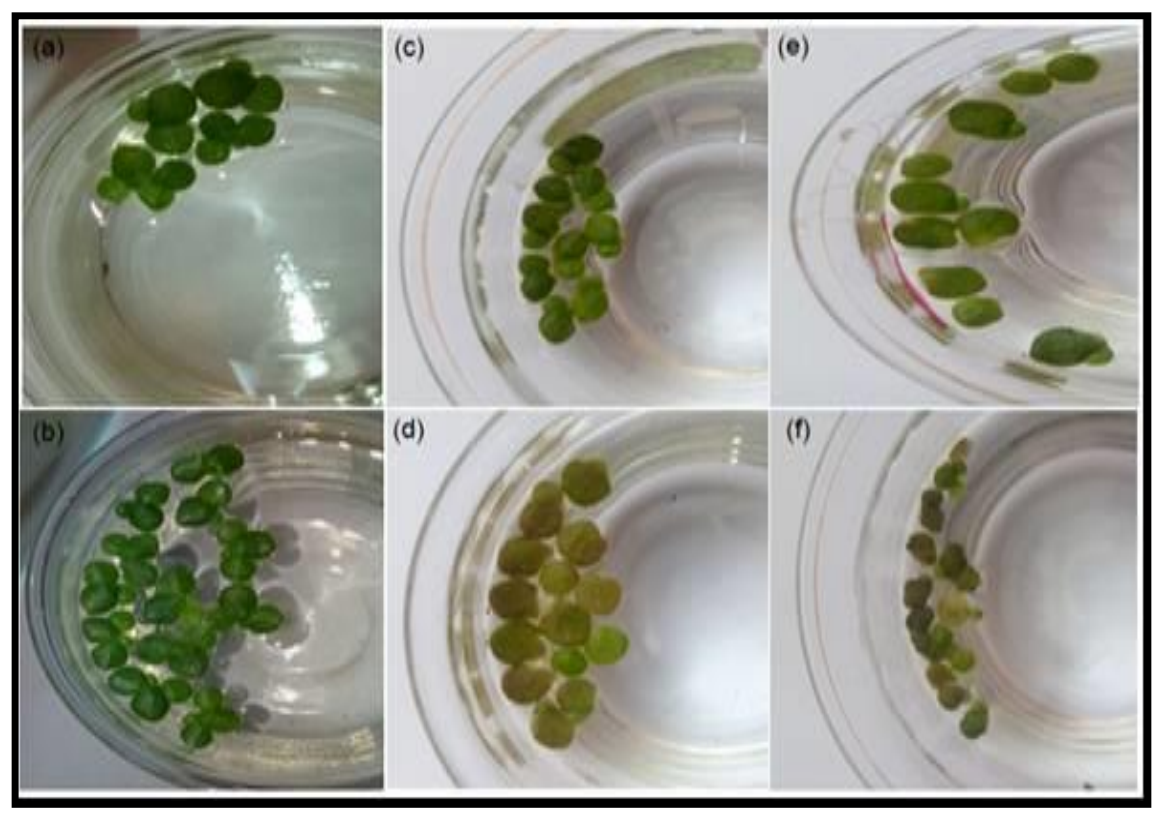



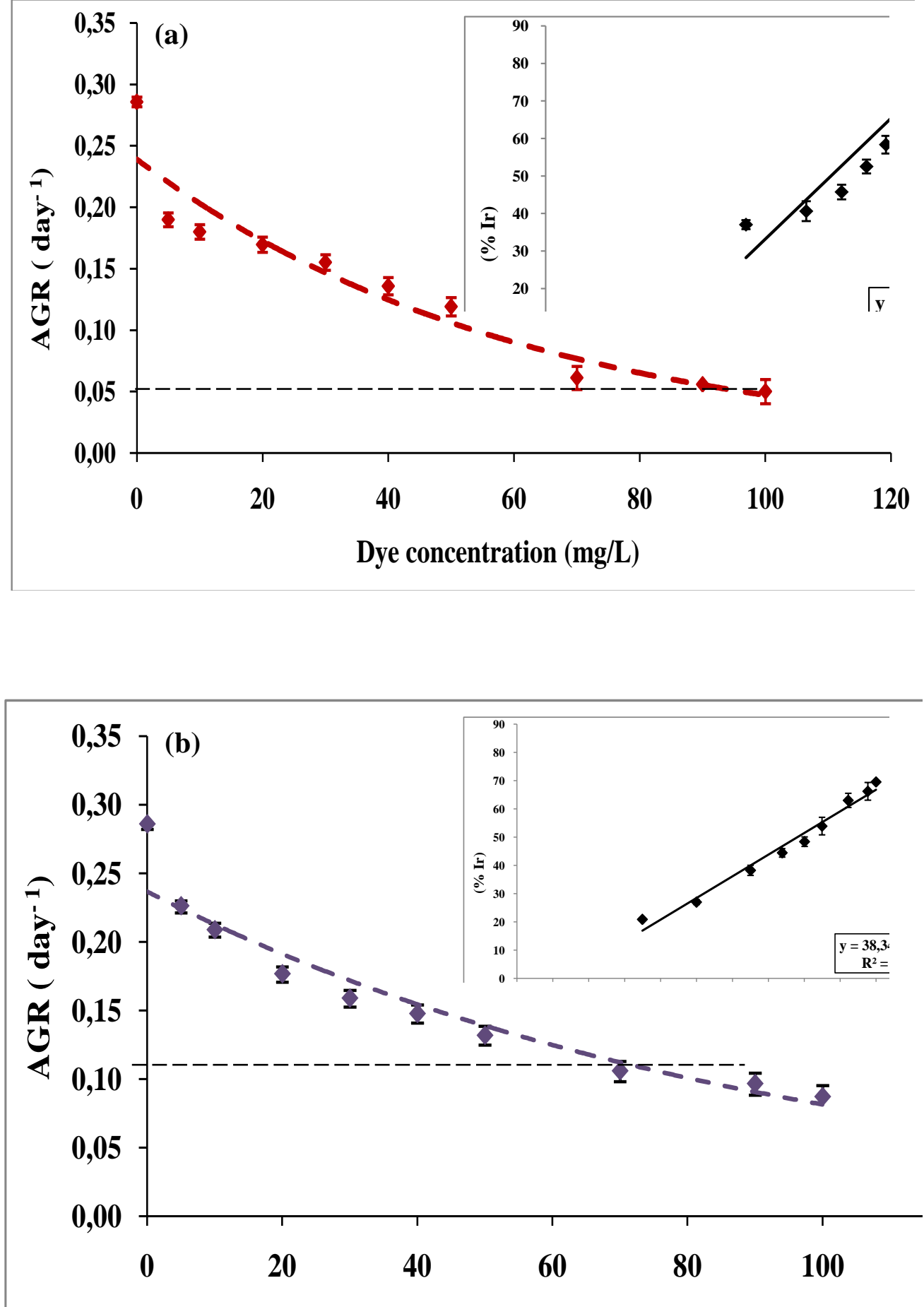

Fig. 3 Average growth rate of $L$. gibba with different concentrations of (a) DR-89 and (b) VB-20. Inserted curves showed percent inhibition of the growth rate versus the logarithmic dye concentration. Broken line indicate minimal growth rate. Vertical bars indicate standard deviation, $\mathrm{n}=3$ 

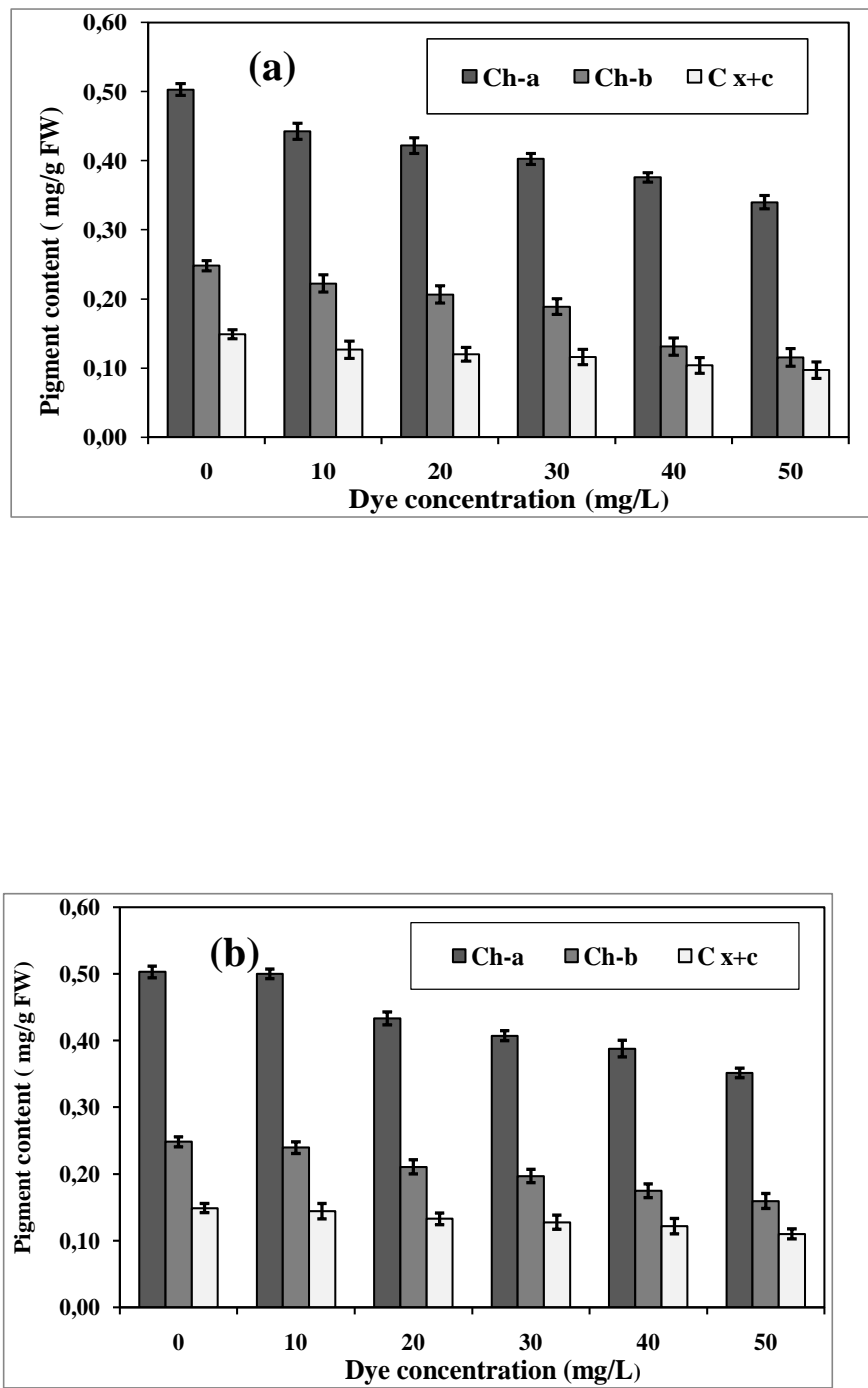